\title{
Prior Knowledge as a Predictor for Persistence
}

\author{
Shirin Riazy ${ }^{1}$, Katharina Simbeck ${ }^{1}$, Robert Woestenfeld ${ }^{2}$ and Marco Traeger ${ }^{2}$ \\ ${ }^{1}$ Hochschule für Technik und Wirtschaft, Berlin, Germany \\ ${ }^{2}$ Mathe im Leben gGmbH, Berlin, Germany
}

Keywords: $\quad$ MOOC, Persistence, Virtual Learning Environment, Early Adopters, Language Analysis.

\begin{abstract}
Prior knowledge has been known to play a large role in the success of MOOCs. Using the virtual learning environment of "Mathe im Advent" (MiA), we have analyzed possibly influential factors for the persistence of students, specifically prior mathematical and language abilities. Furthermore, we have connected linguistic indicators of text difficulty to fluctuations and differences in participating populations. MiA is a German virtual advent calendar offering 24 daily mathematical tasks with over 100,000 users annually. Survey results of the years 2017 and 2018 with over 8,000 participants were further analyzed. The result of the examination is that persistence, as well as the reparticipation of students strongly depended on prior mathematical knowledge and German abilities. This effect was especially visible when the language of the tasks was difficult and their readability was low.
\end{abstract}

\section{INTRODUCTION}

Learning analytics (LA) methods, which serve to "understand and optimize learning and the environments in which it occurs" (Siemens, 2013), have shown to improve outcomes in early adopters (Sclater et al., 2016). While trends and demographics of students in virtual learning environments (VLE) and MOOCs have been studied (e.g. (Ruipérez-Valiente et al., 2019)), Meaney and Fikes (Meaney and Fikes, 2019) have recently proposed that the feedback-loops of the innovations, as well as the research in LA are influenced by the bias of the early adopters. Specifically, they have found that the participants of MOOCs are often well-educated and less in need of learning interventions (Meaney and Fikes, 2019). The educatedness of students as a predictor for success has also been found in other contexts (Kennedy et al., 2015; Smith et al., 2019; Gardner and Brooks, 2018). When it comes to language abilities of students, Crossley and colleagues (Crossley et al., 2015) have found that sophistication and organization of a student's language is a strong predictor for success.

In this paper, we present the results of an evaluation of a German MOOC for students between the ages $9-14$. Specifically, we examine whether prior mathematical and language abilities are predictors for mathematical performance and persistence, leading to the following research questions
RQ1: Does prior mathematical success influence the success in a MOOC?

RQ2: Do prior language abilities influence the success in a MOOC?

RQ3: How do readability and text difficulty influence the participation of students?

To conduct this analysis, survey results of between $8,000-50,000$ students were evaluated.

\section{PREDICTORS OF SUCCESS IN MATHEMATICAL MOOCs}

For the past decade, massive open online courses have been explored as a part of blended learning settings (Borba et al., 2016), with a peak in the years 2012 and 2013 (Lopes et al., 2015). When it comes to mathematical MOOCs, the focus often lies on bridging the gap between school and university (Daza et al., 2013; Najafi et al., 2014; Vihavainen et al., 2013), specifically addressing older, well-educated students (Meaney and Fikes, 2019). Apart from obvious advantages of MOOCs, the permanent availability and large outreach, they have also been found to activate other groups of students than face-to-face teaching (Jiang et al., 2016). In an attempt to analyze and improve user participation, the attrition and performance of students is often predicted (Kennedy et al., 2015). 


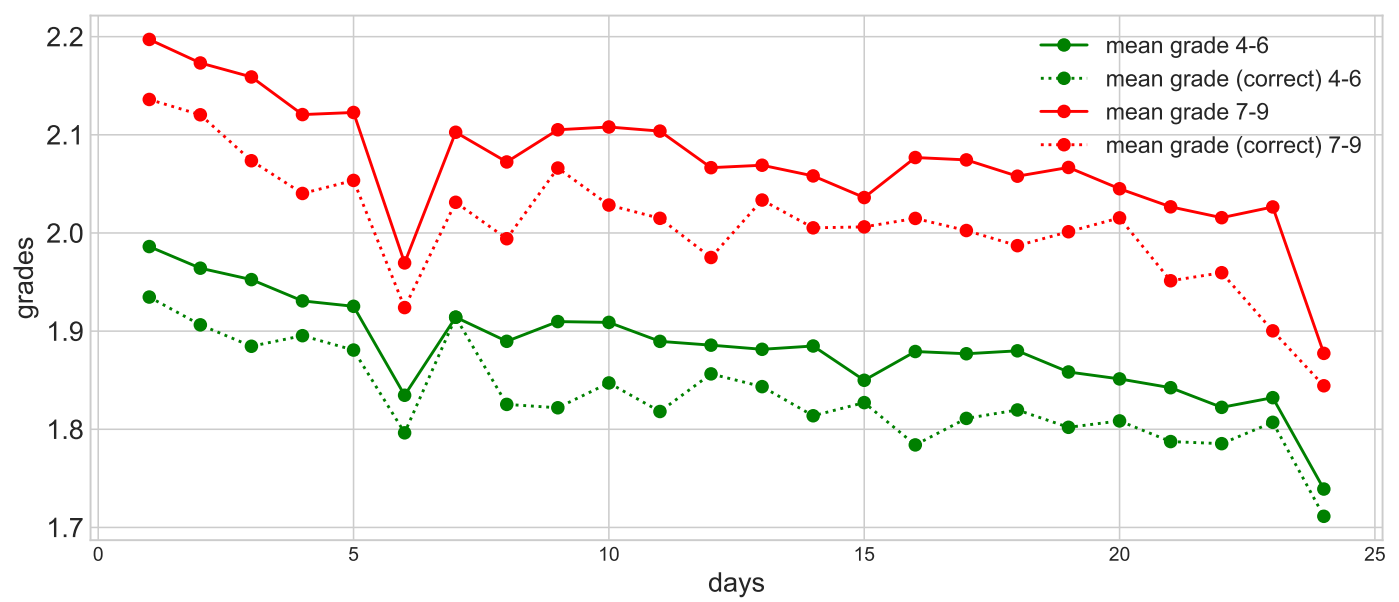

Figure 1: Average Grade ( $1 \hat{=}$ Best Grade, $6 \hat{=}$ Worst Grade) of All Students Who Have Submitted the Solution to a Task for the Calenders "4-6" $\left(r=-0.84161, p<10^{-5}\right)$ and "7-9" $(r=-0.73428, p=0.0004)$, Respectively, of the Advent Calendars in 2017. Dotted: Average Grades of All Students Who Have Submitted Correct Solutions to Those Tasks.

The pre-course performance of students (beside the general course performance and the engagement of students) is one of the most prevalent factors used for the prediction of student performance (Hellas et al., 2018). This falls in line with the constructivists' approaches of learning situations, which emphasize the importance of taking the individual "starting points" of students into account (Kennedy et al., 2015). When predicting computer science students' performance, for example, the majority of the investigations point towards the significance of pre-existing mathematical and programming knowledge (Smith et al., 2019). This has also been observed in a mathematical context (Abeer and Miri, 2014).

However, not only technical skills play a role in the processing of a task. Garman (Garman, 2010) has found that the reading comprehension (measured through a cloze test (Taylor, 1953)) has a significant impact on the scores of students (in a beginning database management class). Wojciechowski and Palmer (Wojciechowski et al., 2005) similarly find that student reading comprehension (among other prior knowledge factors) was a predictor for success in an online undergraduate business course at a community college.

A portion of MOOC performance prediction further deals with language in discussion forums. While several of these publications use NLP-features for the prediction of performance (Crossley et al., 2016; Wen et al., 2014; Yang et al., 2015), others identify social structures (Rosé et al., 2014). Wen et al. (Wen et al., 2014) use linguistic markers of learner motivation (such as "apply" and "need"-words) and Yang et al. (Yang et al., 2015) study the effects of expressed confusion from these forum posts. However, Rose et al. (Rosé et al., 2014) have found the social clustering to be more feasible as a predictor using discussion forum data than the language.

Crossley and colleagues (Crossley et al., 2016) compared forum-based NLP-features with activitybased features and, while the NLP features did predict the completion of the MOOC, adding activity-based features improved the outcome by $10 \%$.

\section{MATHE IM ADVENT}

In the current examination, student data from the advent calendar of "Mathe im Advent" of the years 2017 and 2018 were used. The advent calendar is split into two parts, one calendar for students of the grades 4 6 (ages $9-12$ ), and one for students of the grades 7-9 (ages 12 - 15). Each of these calendars consists of 24 math text problems, which are to be submitted on the $i$-th day of December $(i=1, \ldots, 24)$. On the weekends, the deadline is extended to the following Monday.

The advent calendar is set up as a prize competition, where students who successfully solve all 24 questions may win the main prizes. Aside from the main prizes, competitors who have submitted 20 tasks (out of which 13 must be correct) may win smaller prizes.

Gardner and Brooks (Gardner and Brooks, 2018) have defined MOOCs with the following attributes: Aside from being massive, open and online, they are generally low- or no-stakes, asynchronous in their usage and to be used by a heterogeneous group. "Mathe im Advent" may also be considered low- or no-stakes, since there is no penalty for repeating or failing to 
complete the course (Gardner and Brooks, 2018). However, it is not completely asynchronous, meaning that the tasks generally have to be submitted in the right order, on specific days. Furthermore, the group of students is more homogeneous than in traditional MOOCs, when it comes to demographics and intentions.

\subsection{Comparison to Other MOOCs}

A lot of effort has gone into preparing mathematical courses and lectures for learning in MOOCs. Coursera, EdX, iversity and Udacity, for example, offer mathematical classes at approaching or undergraduate level (Burrill and Ben-Zvi, 2019). When it comes to more basic mathematical knowledge, Khan academy ${ }^{1}$ offers basic mathematical learning materials for classes 1 through 8 . Stanford university offers a self-paced MOOC on how to learn math ${ }^{2}$.

Moving away from classical MOOC formats to competition-based online resources, name-worthy offers are made by Math Kangaroo ${ }^{3}$, as well as classical Math Olympiads ${ }^{4}$, which recently expanded their offerings to online recourses.

The most obvious discrepancy between any of the presented formats and "Mathe im Advent" are the theme-inspired tasks, which also serve the purpose of conveying a Christmas-motivated story in a fictional setting. The materials are openly available as is the prize competition.

\subsection{Rules and Mechanisms of the Advent Calendar}

In the advent calendar, 24 mathematical text questions are (mostly) to be solved on consecutive days. Unlike typical tasks, they are embedded within a fictional storyline with fixed characters. The tasks begin with a description of the setting, similar to a story leading up to a problem. The tasks are designed as multiple choice questions. If a solution was not submitted on time or wrong, the students may apply a "Joker" option (up to three times), where the false/missing answer is treated as a correct answer.

Together with each submission, the participants were able to judge how much they liked the task ("rat-

\footnotetext{
${ }^{1}$ https://de.khanacademy.org/. Last accessed 2019-11-15.

${ }^{2} \mathrm{https} / / /$ lagunita.stanford.edu/courses/Education/

EDUC115-S/Spring2014/about. Last accessed 2019$11-15$.

${ }^{3}$ http://www.mathkangaroo.us/mk/default.html. Last accessed 2019-11-15.

${ }^{4}$ https://www.moems.org/. Last accessed 2019-11-15.
}

ing"), as well as how difficult they thought the task was ("difficulty").

The text questions were designed by pedagogical experts and often influenced by user submissions. If a user-submitted task is chosen for the advent-calendar, this is remarked at the bottom of the page.

\subsection{Surveys before and after the Advent Calendar}

In order to improve their offer, "Mathe im Advent" launches two surveys per season, one at the beginning of December and one at the end. These surveys are voluntary and the registered users are asked via e-mail to participate.

While over 100,000 students participated in the advent calendars of 2017 and 2018, only a portion of these students participated in the surveys before and after the advent calendar. In the survey, they were asked a variety of questions, such as whether they were interested in mathematics in general and whether they thought mathematics was fun. The students had the possibility to opt-out on single questions, as well as the whole survey.

The questions that we have examined were as follows:

1. What was your most recent grade in mathematics?

2. How long did you find the text problems in general?

The answers to all of these questions were given on ordinal scales. For question (1), the answer was given in the German grading system, where 1 equates to the highest grade and 6 is the lowest possible grade. Question (1) was asked in the surveys 2017 and 2018 at the beginning (or prior to the) advent calendar, while question (2) was asked at the end of the competition.

\subsection{Available Data for Analysis}

The data available for analysis was

1. the submission data for 2017 (110,995 participants) and 2018 (101,254 participants), including difficulties and ratings of tasks (Section 3.2),

2. the survey data (Section 3.3),

3. the text problems of "Mathe im Advent" between 2015 and 2018. 
Table 1: Number of Participants Who Have Answered the Questions from Section 3.3 in the Calendars "4-6" and "79", the Years 2017 and 2018 and the Surveys before or after the Advent Calendar.

\begin{tabular}{lllc}
\hline Year & Survey question & $\begin{array}{l}\text { Number of } \\
\text { Participants }\end{array}$ & Survey \\
\hline 2017 & Recent grade & 58,285 & Before \\
\hline \multirow{2}{*}{2018} & Recent grade & 8,733 & Before \\
& Length & 11,243 & After \\
& perception & & \\
\hline
\end{tabular}

\section{METHOD}

The current examination consists of three parts. First, the survey data (see Section 3.3) was connected to the submissions of the 24 tasks in 2017 and 2018, respectively. This was done in order to find submission trends in relation to (estimated) pre-existing mathematical and language skills. As one would expect, there is a falling trend, when it comes to the number of submissions alone. In order to find out, which students tend to persist until the end of the competition, the average grade of all the students having submitted a task per day was computed. Note that this entails only students who chose to take part in the survey. Furthermore, from the participants of the survey, not everyone chose to answer each of these questions. Details for the answers are listed in Table 1.

Note that a single answer to the survey question was used as an indicator for pre-existing knowledge over the course of the whole advent calendar. For example, for each task, the average mathematical grades of the students prior to beginning the advent calendar were evaluated.

The second part of the examination was the evaluation of the daily ratings and difficulties (see Section 3.2) of the tasks. In order to find trends, we have analyzed the means of all ratings and difficulties. Note that the number of submissions for these values differed (ranging from 9,265 to 40,668 in 2018) each day and that they were not only submitted by students, but also potentially by teachers and any registered user who submitted the task.

Thirdly, we have examined the language properties of the tasks and their evolution over the years. Since all of the tasks are formulated as text problems, their correct processing presupposes sufficient language skills. To estimate the coherence of the text problems in general, we have evaluated text statistics, such as the average syllable count, the average word count and so on. All of the variables used for the calculations of text statistics are listed in Table 2.
Table 2: Basic Text Statistics (and Their Explanations) Used for the Analysis of the Tasks.

\begin{tabular}{ll}
\hline Text Statistic & Explanation \\
\hline Syllable count & $\begin{array}{l}\text { Total number of syllables in } \\
\text { a task. }\end{array}$ \\
Lexicon count & $\begin{array}{l}\text { Total number of words in a } \\
\text { task. } \\
\text { Total number of sentences in }\end{array}$ \\
& \begin{tabular}{l} 
a task. \\
\hline
\end{tabular}
\end{tabular}

As the first text statistic, we have used the Flesch reading ease score (FRES) (Flesch, 1948)

FRES $:=180-\frac{\text { total words }}{\text { total sentences }}-58.5 \cdot \frac{\text { total syllables }}{\text { total words }}$.

The FRES score of a task lies in the interval $[0,100]$ and rates the text difficulty from "Very Confusing" (0-29) to "Very Easy" (90-100). The listed version was corrected by Toni Amstad for the German language (Amstad, 1978). The next statistic, the FleschKincaid grade level (FKGL) (Kincaid et al., 1975) calculates a grade level for which the difficulty of a given text would be appropriate. It was developed for the English language and US-american grade system. Above grade level 12 may be interpreted as College level.

$$
\begin{aligned}
\text { FKGL }:= & 0.39 \cdot \frac{\text { total words }}{\text { total sentences }} \\
& +11.8 \cdot \frac{\text { total syllables }}{\text { total words }}-15.59
\end{aligned}
$$

The Wiener Sachtextformel (WSTF, first of three) (Bamberger and Vanecek, 1984) is a readability index by Bamberger and Vanecek. It was specifically developed for German texts and it outputs a grade level for which the difficulty of the text would be appropriate.

$$
\begin{aligned}
\text { WSTF }:= & 0.1935 \cdot \frac{\text { words with } \geq 3 \text { syllables }}{\text { total words }} \\
& +0.1672 \cdot \frac{\text { total words }}{\text { total sentences }} \\
& +0.1297 \cdot \frac{\text { words with }>6 \text { letters }}{\text { total words }} \\
& -0.0327 \cdot \frac{\text { words with } 1 \text { syllable }}{\text { total words }}-0.875 .
\end{aligned}
$$

We have evaluated these text statistics for MiA tasks during the years 2015 until 2018.

\section{RESULTS}

In the following, we will explain the results of the three parts of the examination. 


\subsection{Part 1: Survey Questions}

With at least 8,000 answers per survey question (Table 1), we have connected these answers to the actual task submissions of these users. Students submitting any answer to the task of the day tended to have better grades (mathematics) towards the end of the competition (Figures 1 and 2), with highly significant correlation coefficient $r>0.7$, over the course of the month. The submissions of Jokers were not taken into consideration.

Furthermore, those students who have submitted correct answers to the tasks tended to have higher grades in mathematics, with a tendency towards better grades the end of the month.

On the weekends (around the 6th and 15th in 2017, Figure 1), there were visible peaks in the grades, meaning that students who submitted the tasks on the weekends tended to have better grades. Similarly, there was a peak on the final day (24th), when the holiday break had started.

The second question, the perceived overall length of the text problems, was used as an indicator for the ease of text comprehension of the student. Students who found the task problems rather too short than too long, seemed to persist in relation to all of the students. Moreover, the averaged text length perception of those students who submitted correct answers tended more towards "too short" than "too long".

It should be noted that the text length perception differs more between general submissions and the correct submissions for the calendar "7 - 9" in comparison to the calendar " $4-6$ ".

\subsection{Part 2: Difficulties and Ratings}

As the second part of our examination, we have plotted the averaged perceived difficulties and ratings of the tasks in Figure 3. We have not found a significant difference between the scores of students who submitted correct answers (see Figure 3, dotted line) in comparison to the general scores.

Furthermore, we did not find any trends of rising/falling difficulties or ratings over the course of the month. It was, however, noticeable that the rating and the difficulties of the tasks were closely linked, with highly significant correlation coefficients over $r=0.8$ (see Figure 3).

\subsection{Part 3: Text Statistics}

In the third part of our analysis, we have calculated different text statistics in order to get measures of the difficulties of the language of the text problems. All

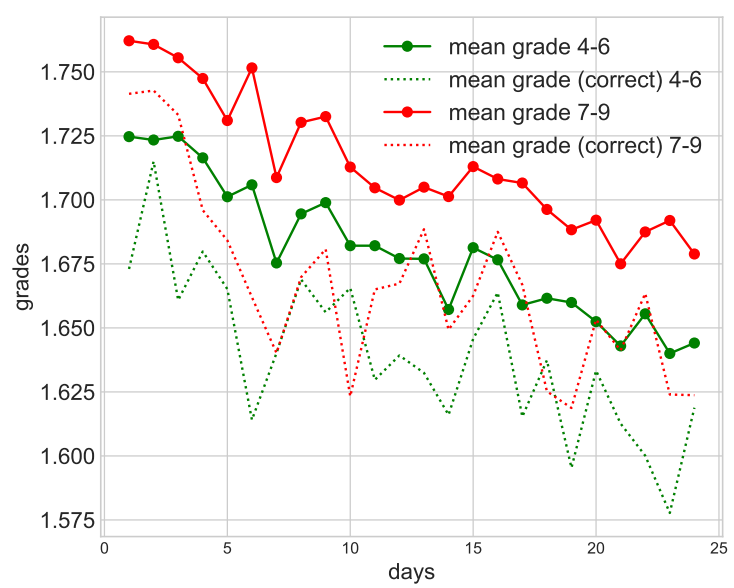

Figure 2: Average Grade $(1 \hat{=}$ Best Grade, $6 \hat{=}$ Worst Grade) of All Students Who Have Submitted the Solution to a Task for the Calenders "4-6" $\left(r=-0.948, p<10^{-5}\right)$ and "7-9" ( $\left.r=-0.91968, p<10^{-5}\right)$, Respectively, of the Advent Calenders in 2018. Dotted: Average Grades of All Students Who Have Submitted Correct Solutions to Those Tasks.

of the measures used are listed in Table 2. The results of the analysis are depicted in Table 3.

While the syllable and lexicon counts seem to have a rising tendency over the years, the sentence count has a clear drop in 2017. This is likely a reason for the increase in text difficulty, when measured by FRES, FKGL and WSTF. The singular increase of the difficulty in 2017 also coincides with the lowest total number of user-submitted tasks within a season.

In general, the difficulties of the text problems seem to be rather high (WSTF between 7 and 9 for the calendar " $4-6$ ") and similar between the two calendars.

\section{DISCUSSION}

All in all, we have detected several trends in the persistence of students in a virtual learning environment. Firstly, there were trends in average grades in 2017 (Figure 1) and 2018 (Figure 2), such that students with higher grades (mathematics) were more likely to persist until the end of the advent calendar, even though the difficulties were not rising (Figure 3). In addition, those students, who are more at ease with longer texts (measured by perceived text length), were more strongly represented towards the end of the competition. As for how well-liked the tasks were, there was a strong connection between the (inverted) ratings and the perceived difficulties of the tasks, meaning that most students preferred easy tasks (highly significant $r>0.8$ ). 

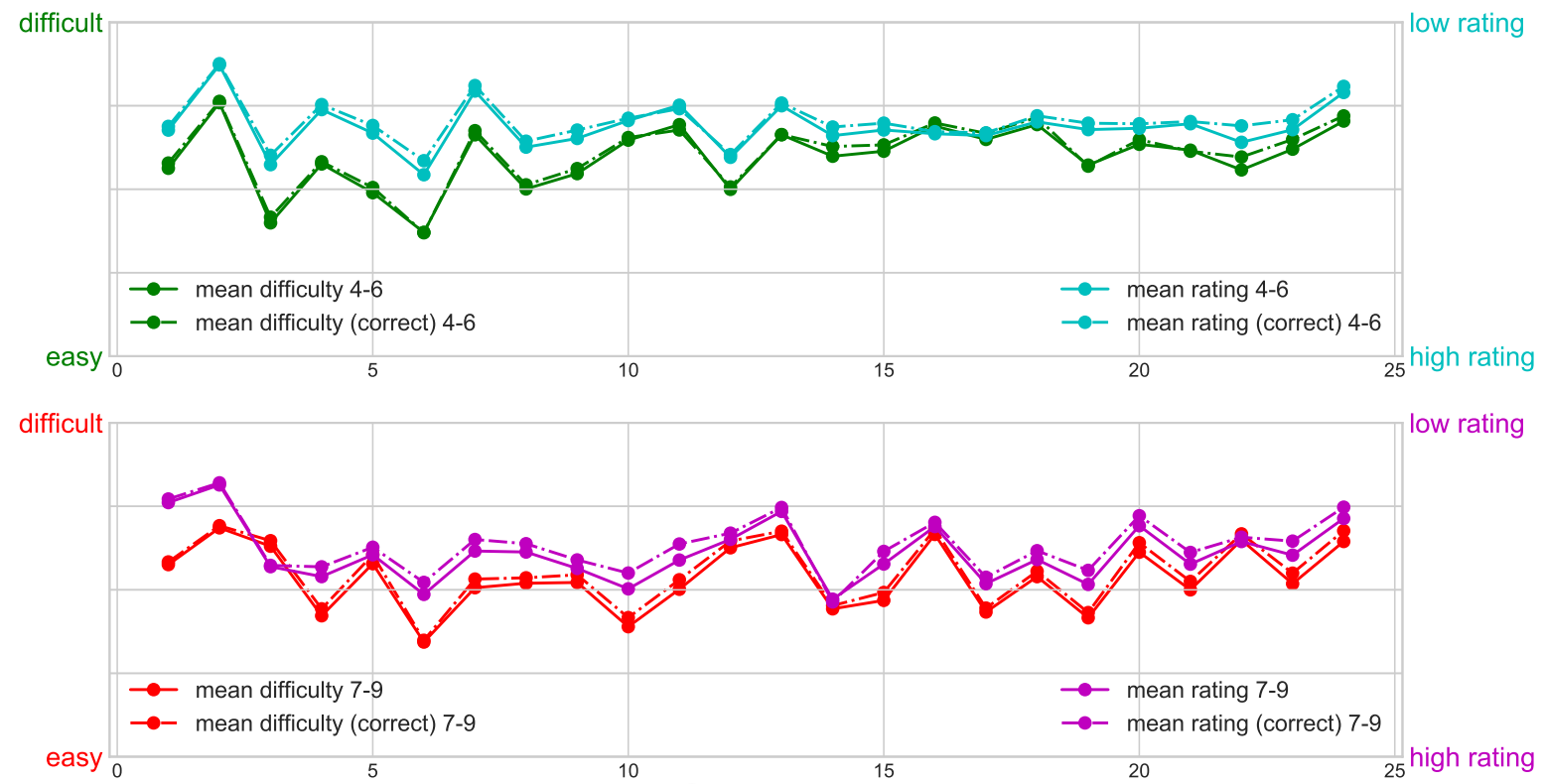

Figure 3: Average Difficulty and Rating of the Advent Calendar Problems per Day for the Calendars "4-6" (Top, Correlation $r=0.858, p<10^{-5}$ between Difficulty and Rating) and "7-9" (Bottom, Correlation $r=0.86107, p<10^{-5}$ between Difficulty and Rating), Respectively, in 2018.

Table 3: Averaged Text Statistics of the "Mathe Im Advent" Math Problem Texts of the Calendars " $4-6$ " and "7 - 9" from 2015 until 2018. "User Tasks" Denotes the Total Number of Tasks (out of 24) That Were Accepted from User Recommendations. Syllables, Lexicon and Sentences Refer to the Basic Text Statistics (See Table 2).

\begin{tabular}{lcccc}
\hline Text statistics & 2015 & 2016 & 2017 & 2018 \\
\hline \multicolumn{5}{c}{ calendar $\mathbf{4 - 6}$} \\
\hline User tasks & 10 & 9 & 7 & 12 \\
Syllables & 435.96 & 441.88 & 441.92 & 527.42 \\
Lexicon & 250.71 & 253.17 & 249.38 & 305.46 \\
Sentences & 15 & 15.33 & 13.75 & 20.42 \\
FRES & 61.03 & 59.48 & 57.38 & 63.49 \\
FKGL & 7.43 & 7.71 & 8.2 & 6.42 \\
WSTF & 8.25 & 8.44 & 8.97 & 7.02 \\
\hline \multicolumn{5}{c}{ calendar 7-9 } \\
User tasks & 12 & 6 & 5 & \\
Syllables & 511.42 & 533.33 & 476.08 & 630.29 \\
Lexicon & 288.17 & 301.46 & 265.79 & 362.38 \\
Sentences & 17.29 & 17.17 & 14.71 & 20.83 \\
FRES & 59.52 & 57.56 & 55.59 & 60.46 \\
FKGL & 7.84 & 8.08 & 8.69 & 7.67 \\
WSTF & 7.46 & 7.63 & 8.55 & 6.71 \\
\hline
\end{tabular}

In the operationalization of the difficulty of the tasks, we have focused specifically on the language properties of the tasks, as the sophistication of language has been found to predict success in MOOCs (Crossley et al., 2015; Abeer and Miri, 2014). Here, we have noticed peaks in all of the statistical measures in the year 2017. The language of the tasks was noticably more difficult than in other years. Furthermore, the total number of participants, as well as the number of participants of the survey, dropped drastically after 2017 (see Table 1). Also, the average of the grades of students participating in the survey in 2018 were far better than the grades of the students from 2017 (see Figures 1 and 2). This points towards a sifting effect of the difficult tasks of 2017.

One of the dangers in the development of virtual learning environments is an excessive focus on (welleducated) early adopters, who are less in need of interventions (Meaney and Fikes, 2019). It is a pedagogical challenge in learning analytics to supply learning environments, which are suitable for a wide range of participants. Furthermore, it is relevant to examine possible obstacles (such as lacking language skills), which are a priori independent of the task at hand.

As a tool for the analysis of text problem difficulties, we have implemented three reading ease / text difficulty indices, which have successfully detected a peak in the difficulty of text problems in 2017. This has likely led to a sifting effect. We propose these measures as possible tools for prior analysis of the tasks, in order to assure consistency and appropriateness. 


\section{CONCLUSION}

In conclusion, the persistence, as well as the reparticipation of students in the "Mathe im Advent" calendar strongly depended on prior mathematical knowledge and command of German language. This effect was especially visible when the language of the tasks was difficult and their readability was low. As an outlook, we would like to further investigate the connection between the perceived level of difficulty of a task and their reading ease scores. This evaluation, in a task-specific setting, would allow to automtically pre-assess tasks with regards to difficulty. Future work will include the prediction of task difficulty using more sophisticated (machine learning) methods.

\section{ACKNOWLEDGEMENTS}

This research has been funded by the Federal Ministry of Education and Research of Germany in the framework "Digitalisierung im Bildungsbereich" (project number 01JD1812A).

\section{REFERENCES}

Abeer, W. and Miri, B. (2014). Students' preferences and views about learning in a MOOC. Procedia-Social and Behavioral Sciences, 152:318-323.

Amstad, T. (1978). Wie verständlich sind unsere Zeitungen? Zürich: Studenten-Schreib-Service.

Bamberger, R. and Vanecek, E. (1984). Lesen, verstehen, lernen, schreiben: die Schwierigkeitsstufen von Texten in deutscher Sprache. Jugend und Volk.

Borba, M. C., Askar, P., Engelbrecht, J., Gadanidis, G., Llinares, S., and Aguilar, M. S. (2016). Blended learning, e-learning and mobile learning in mathematics education. ZDM, 48(5):589-610.

Burrill, G. and Ben-Zvi, D. (2019). Topics and Trends in Current Statistics Education Research: International Perspectives. ICME-13 Monographs. Springer International Publishing.

Crossley, S., McNamara, D. S., Baker, R., Wang, Y., Paquette, L., Barnes, T., and Bergner, Y. (2015). Language to completion: Success in an educational data mining massive open online class. International Educational Data Mining Society.

Crossley, S., Paquette, L., Dascalu, M., McNamara, D. S., and Baker, R. S. (2016). Combining click-stream data with NLP tools to better understand MOOC completion. In Proceedings of the sixth international conference on learning analytics \& knowledge, pages 6-14. ACM.
Daza, V., Makriyannis, N., and Rovira Riera, C. (2013). MOOC attack: closing the gap between preuniversity and university mathematics. Open Learning: The Journal of Open, Distance and e-Learning, 28(3):227-238.

Flesch, R. (1948). A new readability yardstick. Journal of applied psychology, 32(3):221.

Gardner, J. and Brooks, C. (2018). Student success prediction in MOOCs. User Modeling and User-Adapted Interaction, 28(2):127-203.

Garman, G. (2010). A logistic approach to predicting student success in online database courses. American Journal of Business Education (AJBE), 3(12):1-6.

Hellas, A., Ihantola, P., Petersen, A., Ajanovski, V. V., Gutica, M., Hynninen, T., Knutas, A., Leinonen, J., Messom, C., and Liao, S. N. (2018). Predicting academic performance: a systematic literature review. In Proceedings Companion of the 23rd Annual ACM Conference on Innovation and Technology in Computer Science Education, pages 175-199. ACM.

Jiang, S., Schenke, K., Eccles, J. S., Xu, D., and Warschauer, M. (2016). Females' enrollment and completion in science, technology, engineering, and mathematics massive open online courses. arXiv preprint arXiv:1608.05131.

Kennedy, G., Coffrin, C., De Barba, P., and Corrin, L. (2015). Predicting success: how learners' prior knowledge, skills and activities predict MOOC performance. In Proceedings of the fifth international conference on learning analytics and knowledge, pages 136-140. ACM.

Kincaid, J. P., Fishburne Jr, R. P., Rogers, R. L., and Chissom, B. S. (1975). Derivation of new readability formulas (automated readability index, fog count and flesch reading ease formula) for navy enlisted personnel.

Lopes, A. P., Soares, F., and Vieira, I. (2015). Challenges in the creation and development of a mathematics MOOC. In Proceedings of the International Conference of Education, Research and Innovation (ICERI), 8th, pages 1862-1867. IATED.

Meaney, M. J. and Fikes, T. (2019). Early-adopter iteration bias and research-praxis bias in the learning analytics ecosystem. In Companion Proceedings of the 9th International Learning Analytics and Knowledge Conference (LAK'19), pages $513-519$.

Najafi, H., Evans, R., and Federico, C. (2014). MOOC integration into secondary school courses. The International Review of Research in Open and Distributed Learning, 15(5).

Rosé, C. P., Carlson, R., Yang, D., Wen, M., Resnick, L., Goldman, P., and Sherer, J. (2014). Social factors that contribute to attrition in MOOCs. In Proceedings of the first ACM conference on Learning@ scale conference, pages 197-198. ACM.

Ruipérez-Valiente, J. A., Halawa, S., and Reich, J. (2019). Multiplatform MOOC analytics: Comparing global and regional patterns in edX and Edraak.

Sclater, N., Peasgood, A., and Mullan, J. (2016). Learning 
analytics in higher education. London: Jisc. Accessed February, 8:2017.

Siemens, G. (2013). Learning analytics: The emergence of a discipline. American Behavioral Scientist, 57(10):1380-1400.

Smith, IV, D. H., Hao, Q., Jagodzinski, F., Liu, Y., and Gupta, V. (2019). Quantifying the effects of prior knowledge in entry-level programming courses. In Proceedings of the ACM Conference on Global Computing Education, CompEd '19, pages 30-36, New York, NY, USA. ACM.

Taylor, W. L. (1953). "cloze procedure": A new tool for measuring readability. Journalism Bulletin, 30(4):415-433.

Vihavainen, A., Luukkainen, M., and Kurhila, J. (2013). MOOC as semester-long entrance exam. In Proceedings of the 14th annual ACM SIGITE conference on information technology education, pages 177-182. ACM.

Wen, M., Yang, D., and Rosé, C. P. (2014). Linguistic reflections of student engagement in massive open online courses. In Eighth International AAAI Conference on Weblogs and Social Media.

Wojciechowski, A., Palmer, L. B., et al. (2005). Individual student characteristics: Can any be predictors of success in online classes. Online journal of distance learning administration, 8(2):13.

Yang, D., Wen, M., Howley, I., Kraut, R., and Rose, C. (2015). Exploring the effect of confusion in discussion forums of massive open online courses. In Proceedings of the second (2015) ACM conference on learning@scale, pages 121-130. ACM. 